\title{
WACANA ESKATOLOGIS DALAM PUTRU PASAJI
}

\author{
Oleh:

\section{Anak Agung Inten Mayuni ${ }^{1}$, I Wayan Suka Yasa ${ }^{2}$, I Wayan Budi Utama ${ }^{3}$} \\ Intenmayuni59@gmail.com, budiutama904@gmail.com
}

\author{
Universitas Warmadewa ${ }^{1}$ \\ Universitas Hindu Indonesia ${ }^{2}$ \\ Universitas Hindu Indonesia ${ }^{3}$
}

Proses Review 10-25 April, Dinyatakan Lolos 26 April

\begin{abstract}
Putru Pasaji is one of the Hindu literary texts inherited in Bali. It is a text recited to complete the ritual process of mamukur during the funeral ceremony. Its position and function as mantra makes the discourse in the text not fully understood by the Hindus. Having elaborated with the critical discourse analysis by van Dijk focused on the study on the dimensions of the text, social cognition, and social context. Therefore, it is found the dominant discourse in Putru Pasaji is Hindu eschatology. This text conveys the discourse of the importance of offerings in the eschatological context, especially the journey of the spirit after death. The concepts of svarga, naraka, karmaphala, punarbhawa, and moksa connected with the offerings build the eschatological discourse in Putru Pasaji holistically and comprehensively.
\end{abstract}

Keywords: discourse, eschatology, Putru Pasaji, text, context

\begin{abstract}
Abstrak
Putru Pasaji merupakan salah satu teks kesusastraan Hindu yang diwarisi di Bali dan selalu dibacakan dalam ritual kematian 'mamukur'. Kedudukan dan fungsinya sebagai wacana mantra menjadikan wacana di dalam teks tersebut tidak dipahami sepenuhnya oleh umat Hindu. Melalui analisis wacana kritis van Dijk yang memfokuskan kajiannya pada dimensi teks, kognisi sosial, dan konteks sosial ditemukan bahwa wacana yang dominan dalam teks Putru Pasaji adalah eskatologi Hindu. Teks ini menyampaikan wacana keutamaan sesaji dalam konteks ekatologis, yakni perjalanan roh setelah kematian. Konsep svarga, naraka, karmaphala, punarbhawa, serta moksa yang dihubungkan dengan sesaji membangun wacana eskatologis dalam Putru Pasaji secara holistik dan komprehensif.
\end{abstract}

Kata Kunci: discourse, eschatologies, Putru Pasaji. 


\section{PENDAHULUAN}

Masyarakat Hindu di Bali mengapresiasi sastra keagamaannya dengan tradisi mabebasan ${ }^{1}$ yang di dalamnya mencakup aktivitas mamutru atau membaca putru. Menurut Warna, dkk. (1978), kata putru berasal dari urat kata 'pitr' yang berarti "suatu ritual pemujaan kepada leluhur sebagai pelengkap puja pendeta untuk mengantarkan roh mencapai surga". Jadi, substansi teks putru adalah petunjuk ritual pemujaan untuk penuntun roh menuju surga. Dalam aktivitas mamutru, teks putru dibaca dengan lantunan palawakya ${ }^{2}$ tanpa disertai terjemahan dan ulasan. Berbeda dengan tradisi mabebasan pada umumnya yang menerapkan tiga tahap, yakni (a) nguacen 'membaca'; (b) negesin 'menerjemahkan', dan (c) wirasa 'mengungkap makna' (Suarka dalam Yasa, 2009). Hal ini menunjukkan keunikan aktivitas mamutru dibandingkan dengan tradisi mabebasan lainnya di Bali.

Salah satu teks putru yang dibaca setiap upacara mamukur ${ }^{3}$ di Bali adalah Putru Pasaji. Akan tetapi, teks ini belum pernah dikaji para ahli, baik oleh sarjana Barat maupun Indonesia (Titib, 2006). Dalam daftar literatur Jawa 9001900 M yang dirilis Pigeaud (1967) hanya disebutkan keberadaan Putru Payaskara, Putru Pasaji, dan Putru Kalêpasan yang memuat ajaran ritual dan sesaji terkait dunia setelah kematian (world beyond the grave). Semakna dengan itu, Suata (1991) menyatakan bahwa teks putru menceritakan perjalanan roh leluhur (pitara) setelah meninggal dunia dan petunjuk mengenai upacara yang harus dilakukan keturunan (pratisentana) untuk menolong roh leluhur dari kesengsaraan. Artinya, eskatologi menjadi wacana penting dalam Putru Pasaji. Akan tetapi masyarakat Hindu di Bali belum sepenuhnya memahami wacana tersebut, walaupun selalu dibacakan setiap upacara mamukur. Kedudukan dan fungsi Putru Pasaji sebagai ucapan mantra (magico-religious icantantion) dalam upacara

1 Aktivitas menikmati dan memahami teks sastra dalam tradisi umat Hindu di Bali.

2 Cara pelantunan yang khas dalam membaca teks-teks sastra keagamaan Hindu berbentuk prosa.

3 Tahapan upacara kematian dalam tradisi keagamaan Hindu di Bali dengan tujuan menyucikan roh orang yang meninggal dunia. mamukur justru menjadikan wacana eskatologisnya tidak tersosialisasikan secara utuh.

Secara teoretik, wacana keagamaan yang direpresentasikan melalui bahasa bukanlah sekedar ekspresi masyarakat yang bersifat eksternal (dapat dilihat dan didengar), tetapi juga mengandung pengetahuan, kepercayaan, gagasan, dan nilai tertentu, serta dapat berfungsi sebagai pembanding (boundaries), bahkan memiliki nilai penting berkaitan dengan hal-hal yang sifatnya supreme. Bahasa merupakan sistem simbol sekaligus tanda yang memiliki empat struktur atau perangkat dasar dengan fungsi ekspresif, evaluatif, kognitif, dan konstruktif (Triguna, 1997; 2000; 2017). Atas dasar itulah, wacana eskatologis dalam Putru Pasaji penting dikaji untuk memahami kepercayaan, pengetahuan, gagasan, dan nilai masyarakat Hindu di Bali mengenai dunia setelah kematian.

\section{METODE}

Menurut Foucault (dalam Eriyanto, 2003), wacana bukan hanya sekedar rangkaian kata atau proposisi dalam teks lisan maupun tulisan, melainkan sesuatu yang memproduksi yang lain (gagasan, konsep, efek). Wacana yang diungkap dalam kajian ini adalah eskatologis, yakni cabang teologi yang berisi doktrin hari akhir (Bagus, 1996). Gentry Jr. (1982) membedakan dua cabang eskatologi, yakni cosmic eschatology yang menjelaskan doktrin akhir dunia (kiamat) dan personal eschatology yang menguraikan dunia dan kehidupan pascakematian. Putru Pasaji tergolong personal eschatology karena isinya menjelaskan perjalanan roh setelah kematian menurut Hindu. Wacana eskatologis dalam Putru Pasaji dikaji dengan pendekatan critical discourse analysis yang berpijak pada model analisis van Dijk (2015) bahwa wacana memiliki tiga dimensi analisis, yaitu analisis teks, kognisi sosial, dan konteks sosial. Analisis teks mengungkap struktur makro (tematik), superstruktur (skematik), dan struktur mikro pembentuk wacana. Analisis kognisi sosial mengkaji bagaimana teks diproduksi individu atau kelompok pemroduksi teks. Sedangkan analisis konteks sosial melihat bagaimana teks 
dihubungkan lebih jauh dengan struktur sosial dan pengetahuan masyarakat di mana wacana tersebut berkembang (Eriyanto, 2001).

Teks utama yang dianalisis adalah lontar $^{4}$ Putru Pasaji koleksi Griya Tan Bunut, Desa Sibang Kaja, Kecamatan Abiansemal, Kabupaten Badung, Provinsi Bali (selanjutnya disingkat "PP-TB"). Lontar ini berjumlah 27 lempir $^{5}$ dan dalam analisis selanjutnya disingkat $l .1$ hingga l.27. Untuk memastikan bahwa substansi teks tersebut tidak menyimpang dari teks-teks Putru Pasaji yang lain, maka dikaji beberapa teks pembanding dan pendamping, yaitu (a) Lontar Putru Pasaji koleksi Griya Kemenuh, Desa Tunjuk; (b) Transkripsi Lontar Putru Pasaji oleh Wayan Buddha Gautama (2003); (c) Alih Aksara dan Alih Bahasa Lontar Putru Pasaji oleh Tim Alih Aksara dan Alih Bahasa Lontar, Dinas Kebudayaan Provinsi Bali (2008), serta (d) Naskah dan Terjemahan Lontar Putru Pasaji oleh I Dewa Made Dharmawan (2018). Ditemukan perbedaan di antara teks-teks tersebut terutama pada segi kebahasaan, seperti susunan kalimat, diksi, dan unsur-unsur gramatikal lainnya, tetapi substansinya tidak memiliki perbedaan signifikan.

\section{PEMBAHASAN}

\subsection{Analisis Teks}

Dhavamony (1997) menyampaikan bahwa prinsip dasar eskatologi Hindu terpusat pada akibat karma 'tindakan', baik berupa ritual persembahan (sacrifice) maupun hukum tindakan secara umum (karmaphala) yang dihubungkan dengan kedudukan roh setelah kematian. Konsep perjalanan roh, penghakiman, dan tujuan yang dicapai, membangun struktur wacana eskatologis Hindu dalam teks Putru Pasaji. Melalui analisis teks yang mengungkap tema, skema, dan struktur mikro yang membangun wacana eskatologis dalam teks Putru Pasaji, ditemukan interelasi upacara bersaji dan karmaphala dengan kedudukan roh leluhur (pitara) dalam dunia dan kehidupan setelah kematian.

4 Manuskrip yang ditulis di atas daun lontar (Jawa-Bali: ron 'daun' dan tal 'siwalan' atau dalam bahasa Latin 'borassus flabellifer' atau 'palmyra').

5 Helai daun lontar yang diacu sebagai penomoran halaman lontar.
Wacana keutamaan sesaji mendominasi bagian pendahuluan Putru Pasaji, baik otoritas sumber maupun pahalanya, seperti petikan teks berikut ini.

“..., nihan rengön pawarah sang māha pandita, malawas tuha-tuha, pariñcining sarwa saji, pawarah sang adi guru, lěpasnya sakêng pāpa, ruwataning daśa mala, sang mahurip kumingkinang,...".

('..., ini dengarkanlah petunjuk seorang pendeta agung, beliau yang sudah berpengalaman [tentang] perincian semua sesaji, ajaran seorang guru yang utama, pelepas dari kesengsaraan, penyucian sepuluh kekotoran, orang yang hidup wajib mengusahakannya...') (PP-TB, l.1).

Bagian ini menegaskan otoritas sumber Putru Pasaji, yaitu pendeta agung yang telah memahami rincian semua jenis sesaji. Menghaturkan sesaji merupakan kewajiban bagi keturunan atau keluarga orang yang meninggal agar membebaskan roh orang tuanya dari penderitaan ( $p \bar{a} p a$ ) dan menyucikan dari sepuluh kekotoran (daśa mala). Otoritas sumber dan kalimat persuasif pada bagian ini melegitimasi kedudukan teks sehingga penting dijadikan acuan dalam upacara mamukur. Van Dijk (2015), juga menyatakan bahwa bagian pendahuluan menjadi elemen penting dalam wacana untuk memengaruhi pembaca supaya mengikuti seluruh pesan yang diutarakan dalam teks.

Hubungan sesaji dan pahala dalam Putru Pasaji dibedakan menjadi dua, yaitu sesaji yang pahalanya berupa kualitas kelahiran dalam reinkarnasi dan sesaji yang pahalanya berupa durasi kesenangan yang dinikmati pitara di surga, seperti berikut.

“..., persembahkanlah bubur sasuru, [pahalanya terlahir] menjadi manusia utama, nasi putih menjadi perwujudan dharma [manusia bijaksana], nasi merah termahsyur di dunia, nasi kuning memiliki banyak keturunan, nasi hitam memiliki banyak emas, ditambah pelayan dan harta benda, semua benih [yang ditanam] akan berkembang biak dengan 
baik,..." (PP-TB, l.1).

"Ikan tengiri dan kakap [memberikan kesenangan] selama 1 bulan; burung belibis, ijowan, wanten, kadawa, kaliligan, ayam hutan, wuru-wuru, perkutut, balam, dan tekukur [2 bulan]; kijang, menjangan, dan kancil [ 3 bulan]; kerbau hitam dan itik [4 bulan]; landak, trenggiling, dan ruti [ 5 bulan]; biri-biri [ 6 bulan]; kurakura, empas, wakung, penyu, dan kurakura kuning [7 bulan]; babi hutan [8 bulan]; tawon madu [9 bulan]; perahan susu, mentega, dan minyak [10 bulan]; apabila badak, baik kulit, daging, darah, tulang, maupun giginya memberikan kesenangan selamanya di surga" $(P P-T B$, l.2-l.3).

Selain itu, dalam Putru Pasaji juga disebutkan jenis-jenis sesaji yang tidak boleh dipersembahkan kepada pitara karena mengakibatkan kesengsaraan ( $p \bar{a} p a)$, hilangnya kemuliaan, dan memperoleh siksaan neraka (PP-TB, l.4), yaitu lutung, kera, alap-alap, elang, ular, musang, rusa, babi rumahan, anjing, buaya, harimau, kadal, luwak, tikus, wulung, dan ayam. Wacana ini menegaskan kedudukan dan fungsi Putru Pasaji sebagai pedoman upacara mamukur terutama tentang kurban binatang (pasuyajna) karena disebutkan secara rinci jenis-jenis binatang yang boleh maupun tidak boleh dipersembahkan.

Upacara mamukur menjadi syarat utama bagi pitara agar dapat menempuh perjalanan selanjutnya dalam dunia dan kehidupan setelah kematian yang ditandai pernyataan, "ri sampun ta mukti ring bukur, bhumi sayana, pusadi pinakādinya" ('setelah engkau menikmati [sesaji] di bukur, bhumi sayana, pusadi sebagai yang utama') (PP-TB, l.4). Dalam tradisi keagamaan Hindu, bukur adalah sarana utama upacara mamukur sehingga sesaji yang disebutkan sebelumnya dipersembahkan di bukur. Hal ini ditegaskan dengan pernyataan berikutnya bahwa setelah menikmati persembahan di bukur, pitara mulai menyiapkan diri dengan bersuci, berhias, dan berjapa untuk berangkat ke surga. Dalam upacara mamukur di Bali, persiapan ini disimbolkan dengan sarana persembahan berupa, pembersih gigi, pencuci rambut, penghitam mata, minyak wangi, lulur, nasi sesajian selengkapnya, dan air cemani, disertai puja pendeta (PP-TB, l.4).

Wacana perjalanan sang pitara menuju surga dimulai dengan gambaran tentang gunung pitu (tujuh gunung), meliputi gunung Malaya, Suktiman, Windya, Wreksawan, Himawan, Makuta, dan Mahameru. Pada setiap gunung ini tergambar berbagai siksaan yang dialami sang pitara terutama mereka yang tidak atau belum diupacarai ('tan ginawě hayu'). Hubungan ritual sesaji dan karmaphala dibingkai dalam wacana penghakiman pitara di setiap gunung, seperti tidak di-aben (atiwa-tiwa) ${ }^{6}$ setelah meninggal, tidak dibuatkan kajang ${ }^{7}$, orang yang semasa hidupnya tidak pernah berderma, tidak pernah berbuat baik, tidak melaksanakan upacara persembahan (yadnya), tidak percaya agama, tidak mengasihi orang lain, pendeta yang di luar terlihat baik, tetap hatinya busuk (wwikwan), hanya mementingkan harta benda, mati secara tidak wajar (hanyut di sungai, digigit ular, diseruduk sapi atau kerbau, disambar petir, dan bunuh diri), tidak memiliki keturunan, berdusta kepada pendeta, berdusta kepada sesama manusia, tidak membayar kaul, gemar menyiksa binatang, iri hati, dengki, menjual wanita, menghukum orang yang tidak bersalah, meracuni, dan menyihir (black magic) (PP-TB, l.5-l.12).

Setelah melewati tujuh gunung, pitara yang telah diupacarai ('sang pitara lepas') bersiap memasuki surga. Ada satu tempat bernama Krama Mandala yang melukiskan 'ruang antara' gunung pitu dan surga sebagai tempat pitara untuk menyiapkan diri menuju surga di atasnya (PP-TB, l.12). Selanjutnya, disebutkan tujuh tingkatan surga, yakni Swarga Maya; Bhumiloka; Bhwahloka; Mahaloka; Janaloka; Satyaloka; dan Sri Gurunadhi (PP-TB, l.14-l.15). Setelah melintasi tujuh surga ini, pitara akan memasuki surga berikutnya yang berjumlah sembilan sesuai arah penjuru mata angin sebagai kahyangan sembilan dewa (dewata nawa sanga).

6 Tahapan pertama upacara kematian dalam tradisi Hindu di Bali yang bertujuan mengembalikan unsur-unsur panca mahabhuta (tanah, air, api, udara, dan angkasa) pada tubuh manusia dengan cara ditanam atau dibakar.

7 Lukisan dan aksara sakral yang digunakan dalam upacara atiwa-tiwa atau ngaben. 
Karmaphala menentukan jenis surga yang akan ditinggali pitara, seperti ringkasan teks berikut ini.

Iswarapada, surga bagi manusia yang teguh melaksanakan pengendalian diri (brata). Brahmapada, surga bagi manusia yang teguh memuja dan giat mencari nafkah. Buddhapada, surga bagi orang yang selalu mengusahakan kesejahteraan dan gemar berderma. Wisnupada, surga bagi orang yang ikhlas melaksanakan yadnya, gagah berani dalam perang, dan hormat pada pemimpin. Sambhupada, surga bagi orang yang melakukan upacarauntukleluhurnya.Mahesorapada, surga bagi gadis atau perjaka yang berhasil menjaga kesuciannya. Rudrapada, surga bagi orang yang mengasihi jiwa dan raganya, berani dan bertanggung jawab dalam bertindak, setia pada ucapan dan perbuatan. Sangkarapada, surga bagi orang yang setia kepada istri atau suaminya. Siwapada, surga bagi seorang wiku (pendeta) yang taat melaksanakan pengekangan diri (tapa) dan pengendalian diri (brata), serta menguasai pengetahuan tentang moksa, yaitu jalan kembali kepada sumber kehidupan (PP-TB, l.16-l.20).

Dalam Putru Pasaji juga diuraikan bahwa di lambung Siwapada terdapat sembilan surga yang dapat dicapai manusia menurut jenis-jenis perbuatan tertentu semasa hidupnya, seperti berikut.

"Swarga Manik, yakni surga bagi manusia yang tekun belajar, sempurna pengetahuannya, memahami semua tattwa (ajaran kebenaran), cakap dalam pekerjaan, dan pandai mencipta kidung dan simbol-simbol suci. Sri Manuh, yakni surga bagi orang yang tekun bertapa manuh [lugu], tulus ikhlas, tekun bekerja, selalu membuat senang, dan welas asih. Janadewa Pralabda, yakni surga bagi orang yang gemar berkesenian, mencipta seni yang berguna bagi kebajikan, setia dan jujur dalam ucapan. Swarga Byasa, yakni surga bagi orang yang suka berderma daun, emas, dan permata. Gandalango, yakni surga bagi orang yang memuja dan mempersembahkan sesaji saat hari suci, tekun menjalankan brata kembang (memakan bunga) dan brata Saraswati, tidak memakan sirih, dan berpuasa saat hari suci. Maniratna Kanaka, yakni surga bagi orang yang tulus mengasihi semua makhluk. Nala Gambirapada, yakni surga bagi orang yang setia dalam cinta dan berani berperang menegakkan kebajikan (dharma). Swargapada, yakni surga bagi orang yang selalu berbuat baik, berbudi luhur, dan berwatak bajik. Windu Pepet, yakni surga bagi orang yang berhasil melakukan tapa brata, bebas dari segala nafsu indriya, menjadi pengembara (spiritual) yang baik, dan selalu memuja saat bulan terang."

Dengan demikian, surga tertinggi menurut Putru Pasaji adalah Siwapada sebagai tempat bagi pendeta yang tekun melaksanakan tapa brata dan menguasai pengetahuan tentang moksa atau kembali pada sumber kehidupan. Bila dikaitkan dengan sesaji berupa warak (badak), maka orang yang mencapai moksa berarti tinggal selamanya di Siwapada. Di sini, hakikat moksa dipahami sebagai keadaan 'tinggal atau menyatu di alam Siwa' dan mengalami kebahagiaan selamanya tanpa disertai duhka atau kesedihan (suka tan pawali dukha). Jadi, wacana eskatologis dalam Putru Pasaji meliputi ajaran naraka (neraka), swarga (surga), punarbhawa (reinkarnasi), dan kembali kepada sumber kehidupan (moksa) yang dihubungkan dengan persembahan sesaji dalam upacara mamukur.

\subsection{Analisis Kognisi Sosial}

Dalam rangka memahami kognisi pencipta teks Putru Pasaji, maka teori intertekstualitas relevan digunakan. Asumsi dasar teori ini bahwa tidak ada sebuah teks yang benar-benar mandiri sehingga harus dibaca dengan latar belakang teks-teks lain (Teeuw, 1984). Teks-teks lain menjadi teladan, acuan, atau kerangka dalam penciptaan teks-teks baru, kendati dalam penciptaannya dapat melahirkan penyimpangan 
dan transformasi (Yasa, 2009). Teks transformatif mempunyai tiga kemungkinan, meliputi (1) teks afirmatif normatif, yakni memantapkan dan menguatkan struktur, norma, dan nilai dalam masyarakat; (2) teks restoratif, yakni mempertahankan norma-norma yang dalam kenyataan sosial telah meluntur atau menghilang; dan (3) teks inovatif atau revolusioner, yakni merombak nilai yang telah mapan (Jauss dalam Teeuw, 1984; Suarka, 2009; Yasa, 2009).

Terkait dengan teori tersebut, pernyataan Suparta (2016) dapat dijadikan pijakan dalam analisis intertekstualitas Putru Pasaji, sebagai berikut.

“Teks PK [Putru Kalěpasan] MerapiMerbabu merupakan teks pertama dalam khazanah naskah Jawa yang menjelaskan secara rinci tentang tata upacara sesaji yang ditujukan bagi penyucian dan pemujaan roh leluhur dalam ritual Sraddha pada masa Jawa Kuno. Memang masyarakat Hindu di Bali mengidentikkan Putru Kalepasan dengan Putru Pasaji dan Putru Sayaskara sebagai teks sakral yang dibaca dalam tradisi mamutru".

Mengacu pernyataan Suparta (2016) bahwa Putru Kalepasan Merapi-Merbabu merupakan naskah Jawa Kuno pertama bergenre tutureskatologis yang menyajikan rincian sesaji dalam pitra yadnya, maka terbuka kemungkinan bahwa teks ini merupakan hipogram dari Putru Pasaji. Mengingat ditemukan sejumlah kesamaan dan perbedaan dari kedua teks tersebut. Apabila hipotesis ini diterima, maka model penerapan hipogram teks Putru Pasaji lebih bersifat pengutipan (excerpt) dan penggubahan (modification). Excerpt bahwa teks Putru Pasaji diproduksi dengan mengutip bagian dari Putru Kalepasan yang spesifik mewacanakan sesaji dalam relasi eskatologis terutama terkait upacara mamukur. Modification bahwa dalam produksi teks Putru Pasaji, pengarang melakukan perubahan dan memanipulasi teks Putru Kalepasan, seperti penokohan, pemilihan diksi, susunan kalimat, dan alur wacana. Perbedaan nama-nama sesaji, nama-nama gunung, dan nama-nama surga menjadi beberapa contoh modifikasi teks Putru
Pasaji dari hipogramnya.

Dalam proses modifikasi teks ini, tampaknya penggubah Putru Pasaji juga menyertakan berbagai pengetahuan yang diperoleh dari sumber-sumber yang lain. Sejumlah hipogram teks Putru Kalepasan yang dijelaskan Suparta (2016) dalam kajiannya, seperti Manawadharmasastra dalam konteks upacara Sraddha ('pitra yadnya'), Sarasamuccaya tentang pitratarpana ('sesaji bagi pitara atau leluhur'), Sumanasantaka dan Nagarakertagama tentang konsep bukur ('sarana tempat ber-sthana leluhur untuk menikmati sesaji'), Wretisasana mengenai kurban binatang, Adiparwa mengenai siksaan bagi orang yang tidak memiliki keturunan, dan teks-teks lainnya juga dapat diberlakukan terhadap hipogramik Putru Pasaji. Pengaruh ideologi Siwaistik cukup kuat mewarnai wacana eskatologis dalam Putru Pasaji, seperti ditandai kedudukan Siwapada sebagai surga tertinggi.

\subsection{Analisis Sosial Kontekstual}

Wacana selalu muncul dalam konteks tertentu, baik sebagai penyadaran, pencerahan, maupun perlawanan ideologis terhadap berbagai praktik sosial yang sedang berkembang di masyarakat. Hal ini sejalan dengan pendapat Titscher, et,al (2009) bahwa analisis wacana kritis mengkonseptualisasi bahasa sebagai praktik sosial dan mencoba membuat pembaca sadar terhadap pengaruh resiprokal (timbal balik) antara bahasa dan struktur sosial yang tidak disadari.

Mengacu pendapat Suparta (2016) bahwa teks Putru Kalepasan Merapi-Merbabu adalah teks tutur eskatologis pertama yang lahir pada abad ke-16, maka keadaan masyarakat Jawa pada abad tersebut menjadi konteks kemunculannya. Abad ini adalah masa kemunduran agama Hindu pascaruntuhnya Majapahit dan berkembangnya agama Islam. Pusat-pusat aktivitas kesusastraan Jawa Kuno dan agama Hindu mulaimenghilang (Zoetmulder, 1985). Anderson (1990), bahkan menegaskan bahwa periode dari tahun 1500 hingga tahun 1750 merupakan Abad Kegelapan Jawa. Akan tetapi, pada abad ke-16 masih muncul sekelompok pecinta sastra yang menyelamatkan naskah-naskah Jawa Kuno ke wilayah sekitar 
gunung Merapi dan Merbabu (Wiryamartana, 1994). Keberadaan naskah koleksi MerapiMerbabu menunjukkan bahwa kesusastraan Jawa Kuno tetap berkesinambungan pascaruntuhnya kerajaan Majapahit, sebagian berlanjut di Jawa Tengah dan terus berkembang pesat di Bali (Suarka, 2009).

Dengan menjadikan abad ke-16 sebagai latar sejarah munculnya naskah-naskah tutureskatologis abad ke-16, seperti Putru Kalepasan yang berhubungan hipogramik dengan Putru Pasaji, maka perkembangan agama Islam menjadi latar sosial kemunculannya. Wacana eskatologis Islam yang menyebar di masyarakat mendorong para pecinta sastra Jawa Kuno penganut Hindu yang masih bertahan - untuk melakukan penyadaran, pencerahan, dan perlawanan melalui teks. Bentuk perlawanan ini dapat disimak dari wacana eskatologis dalam Putru Pasaji yang lebih menekankan pada konsep 'neraka' dan 'surga'. Apabila dicermati lebih jauh, wacana neraka dan surga cenderung mendominasi ajaran eskatologis dalam Putru Pasaji, dibandingkan reinkarnasi (punarbhawa) dan kelepasan (moksa).

Aspek-aspek eskatologis Islam tampaknya menginspirasi pemroduksi teks Putru Pasaji, sekaligus sebagai strategi kontrahegemoni. Hal ini dapat diungkap melalui perbandingan sejumlah konsep dalam wacana eskatologis Islam dengan Putru Pasaji, sebagai berikut. Pertama, konsep "berada di sisi Allah" sepadan dengan Siwapada "tinggal di alam Siwa" sebagai surga yang tertinggi. Kedua, gambaran neraka dan surga sama-sama ditemukan dalam wacana estakologi Islam maupun Putru Pasaji, tetapi Putru Pasaji mempertahankan konsep-konsep neraka dan surga spesifik dalam Hindu sebagai kontrahegemoni. Ketiga, iman, akhlak, dan ibadah sebagai penentu surga atau neraka dalam Islam, juga disajikan dalam Putru Pasaji. Keempat, kepercayaan bahwa doa sanak famili dapat menolong roh dari siksaan neraka dan mendapatkan ridla Allah, juga menjadi dimensi penting wacana eskatologis dalam Pasaji bahwa ritual sesaji, puja, dan mantra penting untuk mengantarkan pitara mencapai surga.
Perbandingan konsep-konsep eskatologis tersebut menunjukkan hubungan yang kuat antara produksi wacana eskatologis dalam Putru Pasaji dengan situasi kemasyarakatan yang melatarinya. Penekanan aspek-aspek yang 'sepadan' dengan ajaran Islam menjadi strategi wacana yang diterapkan, tanpa meninggalkan esensi ajaran Siwa yang diwarisi sebelumnya. Dengan kalimat lain, wacana eskatologis dalam Putru Pasaji dihadirkan sebagai tanggapan kawi-wiku (pencipta teks) atas situasi sosial abad ke-16 yang ditandai perkembangan dan penyebarluasan agama Islam di Jawa sebagai penyadaran, pencerahan, dan perlawanan terhadap wacana eskatologis Islam yang menyebarluas di masyarakat.

\section{PENUTUP}

Wacana eskatologis dalam Putru Pasaji bermuara pada keutamaan sesaji sebagai dasar bagi perjalanan roh (pitara) di kehidupan setelah kematiannya. Roh yang belum diupacarai tidak dapat melanjutkan perjalanan menuju surga dan akan mendapatkan hukuman di tujuh gunung (gunung pitu) sesuai perbuatan (karma) semasa hidupnya. Surga dapat dicapai oleh roh yang telah diupacarai (sang pitara lěpas) yang jenis-jenisnya ditentukan oleh karma. Sesaji memiliki peranan dalam menentukan jenis punarbhawa, selain karmaphala. Konsep moksa digambarkan sebagai keadaan berada di alam Siwa (Siwapada) selama-lamanya.

\section{Ucapan Terimakasih}

Artikel ini merupakan bagian dari disertasi penulis berjudul "Putru Pasaji: Wacana Eskatologis dalam Pitra Yadnya”. Terima kasih dan apresiasi setinggi-tingginya disampaikan pada Prof. Dr. I Wayan Suka Yasa, M.Si, selaku promotor dan Dr. I Wayan Budi Utama, selaku kopromotor. Spesial kepada Prof. Dr. Ida Bagus Gde Yudha Triguna, MS, yang membimbing secara khusus, dan sejumlah pihak yang telah membantu dalam penulisan disertasi ini. 


\section{DAFTAR PUSTAKA}

Anderson, Benedict R. O'G. 1990. Language and Power Exploring Political Cultures in Indonesia.

London: Cornell University Press.

Bagus, Lorens. 1996. Kamus Filsafat. Jakarta: Gramedia Pustaka Utama.

Darmawan, I Dewa Made. 2018. Teks dan Terjemahan Putru Pasaji (tidak dipublikasikan).

Dhavamony, Mariasussai. 1995. Fenomenologi Agama. Penerjemah: Kelompok Studi Agama Driyarkara. Yogyakarta: Kanisius.

Eriyanto. 2001. Analisis Framing: Konstruksi, Ideologi, dan Politik Media. Yogyakarta: LKiS. 2003. Analisis Wacana: Pengantar Analisis Teks Media. Yogyakarta: LKiS.

Gautama, Wayan Budha. 2003. Putru Pasaji: Transkripsi Lontar Putru Pasaji. Surabaya: Paramita.

Gentry JR., Kenneth L. 1992. He Shall have Dominion, A Postmillenial Eschatology. Texas: Institute for Christian Economics.

Mardiwarsito, L. 1992. Kamus Jawa Kuna (Kawi) - Indonesia. Ende-Flores: Nusa Indah.

Pigeaud, Theodore G. Th. 1967. Synopsis of Javanese Literature 900 - 1900 AD. Leiden: Martinus Nyhoff, The Hague.

Suarka, I Nyoman dan Sulastin Sutrisno. 2009. “Wacana Sangkan-Paran dalam Kakawin Aji Palayon: Sebuah Analisis Semiotik." Artikel dalam Linguistika: Buletin Ilmiah Progam Magister Lingustik, Vol. 16 (2009), September 2009, hal. 1-18. Denpasar: Program Magister (S2) dan Doktor (S3) Lingusitik Universitas Udayana bekerjasama dengan .

2018. "Fungsi Dharmagita dalam Yadnya". Makalah disajikan dalam Pelatihan Dharmagita yang diselenggarakan Kantor Kementerian Agama Kota Denpasar, tanggal 23 Juli 2018.

Suata, I Putu Gede. 1991. “Perjalanan Arwah Ke Surga”, dalam Warta Jagatnata, No. 14. Januari 1991, hal. 9-14.

Suparta, I Made. 2016. "Putru Kalepasan Merapi-Merbabu: Kajian Filologis dan Konsep Eskatologis Jawa Kuno Abad ke-16 Masehi”, Ringkasan Disertasi. Depok: Fakultas Ilmu Pengetahuan Budaya, Program Studi Ilmu Susastra, Universitas Indonesia.

Teeuw, A. 1984. Sastra dan Ilmu Sastra: Pengantar Teori Sastra. Jakarta: Dunia Pustaka Jaya.

Tim Alih Aksara dan Alih Bahasa Lontar. 2008. Alih Aksara dan Alih Bahasa Lontar Putru Pasaji. Denpasar: Dinas Kebudayaan Provinsi Bali.

Titscher, Stefan, dkk. 2009. Metode Analisis Teks dan Wacana. Cetakan 1. Yogyakarta: Pustaka Pelajar.

Titib, I Made. 2006. Persepsi Umat Hindu di Bali Terhadap Svarga, Naraka, dan Moksa dalam Svargarohanaparva. Paramita. Surabaya.

Triguna, Ida Bagus Gde Yudha. 1997. "Mobilitas Kelas, Konflik, dan Penafsiran Kembali Simbolisme Masyarakat Hindu di Bali." Disertasi tidak dipublikasikan. Universitas Pajajaran Bandung.

2000. Teori Tentang Simbol. Denpasar: Widya Dharma.

2017. Budaya Inspiratif \& Pembangunan Karakter. Denpasar: Program Pascasarjana Universitas Hindu Indonesia.

Wiryamartana, I Kuntara. 1994. "Merbabu-Merapi sebagai Wilayah Kajian”. Makalah dibawakan dalam Temu Ilmiah VIII, Pengelola Studi Bahasa-Sastra Jawa Tingkat Nasional di Surabaya.

Yasa, I Wayan Suka. 2009. Rasa: Daya Estetik - Religius Geguritan Sucita. Denpasar: Sari Kahyangan Indonesia.

Zoetmulder, P.J. 1985. Kalangwan Sastra Jawa Kuno Selayang Pandang. Cetakan ke-2. Jakarta: Jambatan.

1995. Kamus Jawa Kuno-Indonesia. Jakarta: Gramedia dan Instituut voor Taal-, Land- en 
Volkenkunde (KITLV) bekerjasama dengan S.O. Robson.

Van Dijk, Teun A. 2015. "Critical Discourse Studies." Discourse of Society, in http://www.discourses. org/OldArticles/Critical\%20Discourse\%20Studies.pdf. Diakses pada 29 November 2018.

\section{Manuskrip:}

1. Lontar Putru Pasaji koleksi Griya Tan Bunut, Desa Sibang Kaja, Kecamatan Abiansemal, Kabupaten Badung (milik pribadi Ida Bagus Made Jelantik).

2. Lontar Putru Pasaji koleksi Griya Kemenuh, Desa Tunjuk, Kecamatan Tabanan, Kabupaten Tabanan (milik pribadi Ida Pedanda Gede Giriputra). 